\title{
FACULTY AT TOP EE/CS RESEARCH UNIVERSITIES
}

\section{Dr. Anil Saigal, Tufts University}

Anil Saigal is a Professor in the School of Engineering at Tufts University. He received his doctorate from the Georgia Institute of Technology.

Mr. Arun Karthik Saigal, Massachusetts Institute of Technology

Arun Saigal is a graduate student in the Department of Electrical Engineering and Computer Science at MIT. 


\title{
Faculty At Top EE/CS Research Universities
}

\author{
Anil Saigal $^{1}$ and Arun Saigal ${ }^{2}$ \\ ${ }^{1}$ Tufts University, Medford, MA 02155 \\ email: anil.saigal@tufts.edu \\ ${ }^{2}$ Massachusetts Institute of Technology, Cambridge, MA 02139 \\ email: aksaigal@mit.edu
}

\begin{abstract}
Does it matter where you do your doctorate if your goal is to become a faculty member at a top electrical engineering / computer science research university? A number of criteria have been used to rank engineering institutions including total research and development expenditures, federally sponsored research and development, number of members of the National Academies, significant faculty awards, size of endowment and annual giving, and mean GRE scores of enrolling graduates students, among others. As per the latest U.S. News and World Report rankings, the top 10 ranked universities are MIT, Stanford, UC-Berkeley, Illinois-Urbana Champaign, Georgia Tech, CalTech, Carnegie Mellon, Michigan-Ann Arbor, Cornell, Princeton and Purdue. However, as a graduating EE/CS doctoral student, what are your chances of receiving an offer at one of these top-ranked institutions. This study looks at the distribution of faculty at these institutions and where they received their doctorate. More than $67 \%$ of the faculty members at the 10 top-ranked institutions have received their doctorate from these institutions themselves with nearly $38 \%$ of them from the top three. If you include other Ivy League universities and major international universities, this number increases to nearly $80 \%$. Among the top three institutes MIT, Stanford and UC-Berkeley, nearly twothirds of the faculty have received their doctorate from one of these three institutions themselves, $80 \%$ of them from the top 10 ranked institutions, and more than $90 \%$ from top 10 , other Ivy League universities and major international universities. More than $40 \%$ of MIT faculty has received their doctorate from MIT itself. These numbers are significantly higher as compared to some other fields. Some of the factors which contribute to this are the local employment market for the graduates and their availability and interest at a future date, and tracking and mentoring of future faculty members by these institutions. MIT, Stanford and UC-Berkley are just about equally successful in placing the highest number of its graduates at other top ranked institutions. Besides the top three, CalTech, CMU and Princeton are the only institutions to have successfully placed their graduates at each of the top 10 ranked institutions. Public universities are in general more diverse and have a higher percentage of faculty members from non top 10 ranked institutions. Even though at other institutions, the diversity from which faculty have received their doctorates increases, it appears that the institution where graduates receive their doctorate affects their employability as a faculty member at top ranked electrical engineering / computer science programs.
\end{abstract}




\section{Background}

"The common wisdom is that you'll never secure a position at a university that is higher ranked than your PhD program. While there are notable exceptions, this tends to hold true for most people, across all disciplines.”

"In my field, most professors at top-10 schools also got their degrees at top-10 schools."

These are some of the statements on the web in response to the question "Does it matter where you get your PhD?” In 2005, Wu collected degree information for over 5,000 full-time faculty members in six disciplines (chemistry, economics, English, history, mathematics, and sociology) who were employed at liberal arts colleges and universities ranked as the top 25 in the U.S. News and World Report rankings ${ }^{2}$. He cross tabulated information for these faculty members to determine who among them had obtained their PhDs from departments that were ranked among the top 10 and 20 programs in the U.S. News rankings for each discipline.

While the U.S. News rankings are often maligned for the subjectivity of their quality ratings, Wu's findings do suggest some underlying validity in the ratings, at least as a predictor for academic employment. Over 67\% of faculty employed in Economics departments of top-rated "national universities" had degrees from the top 10 schools, as compared to approximately 59\% in History and 57\% in English departments ${ }^{2}$.

Townsend expanded the analysis for History, looking beyond the top 25 programs to a much wider range of departments employing history PhDs, while also including faculty who are not employed full time. He found that faculty employed in the top quartile of programs conferring history $\mathrm{PhDs}$ in the U.S. News rankings, were a relatively closed circuit of $\mathrm{PhDs}$ and employment. Almost $80 \%$ of the full-time faculty listed at those programs received their degrees from either the same program or another program in the same tier of the rankings.

The dominance of PhDs from the top-tier universities diminishes sharply when one looks at history departments that do not confer a history $\mathrm{PhD}$. Only $44 \%$ of full-time faculty at these departments earned PhDs from a top-tier institution, while 33\% earned their degrees from one of the other domestic programs, and $12 \%$ earned their degrees overseas ${ }^{3}$.

There are two perceptions/myths about faculty hiring within the engineering disciplines at the top research universities. First, top research universities typically hire from other top research universities. Second, universities do not hire their own doctorates. In previous research, the authors looked at the distribution of faculty at the top 10 mechanical engineering institutions and where they received their doctorate. They found that more than $60 \%$ of the faculty at the 10 topranked universities received their doctorate from these 10 top-ranked institutions themselves with nearly $45 \%$ of them receiving their doctorates from the top four ranked universities. If one includes other Ivy League universities and major international universities such as the University of Cambridge, this number increases to nearly $80 \%{ }^{4}$. 
This paper attempts to quantify the hiring pattern in the field of EE/CS at the top 10 electrical engineering research programs in the United States. This is important as people who have trained at great length and expense to be researchers confront a swindling number of academic jobs ${ }^{5}$. In 1974, fewer than 30\% of all science and engineering (S\&E) Ph.D.s were working in industry, and more than $45 \%$ were in tenure-track faculty positions. By 1999, the trend had reversed with nearly 38\% S\&E Ph.D.s who had received their training in the United States were working in industry, whereas about $25 \%$ were working in a tenure-track position in academe 5 .

\section{Methodology}

Colleges and universities now customarily provide information about their faculty members on their websites, including details such as year of hiring, dates and institutions where degrees were earned, and research specialties. The information for this article was obtained from the websites of the top 10 research universities in electrical engineering during Fall 2012, as determined by the U.S. News and World Report rankings for 2012. This paper includes data only for faculty members holding permanent positions at the rank of assistant, associate, or full professor. Information about individuals holding temporary and adjunct positions, emeriti faculty, and individuals whose doctoral school could not be identified were excluded from the analysis. The resulting data set includes information for eleven hundred and seventy seven $(\mathrm{N}=1177)$ faculty members at these universities.

This paper looks at the 2012 U.S. News rating of the top 10 electrical engineering programs at research universities in the United States. Note that although the U.S. News rankings were used, there is a high correlation between different ranking schemes. Hence key results will likely not significantly differ had another ranking been used. Also note that this study looks at EE/CS faculty from the top 10 electrical engineering research institutions. This is because a number of these institutions had joint electrical engineering and computer science departments. The top 10 ranked programs in electrical engineering used in this study are the Massachusetts Institute of Technology (MIT), Stanford University, the University of California at Berkeley (UC-Berkeley), the University of Illinois at Urbana Champaign (UIUC), the Georgia Institute of Technology (Georgia Tech), the California Institute of Technology (CalTech), Carnegie Mellon University (CMU), the University of Michigan at Ann Arbor (Michigan-Ann Arbor), Cornell University, Princeton University and Purdue University ${ }^{6}$.

The number of doctorates in electrical engineering awarded by all US academic institutions is around 1900 per year for the past five years ${ }^{7}$. Of these, the number of doctorates in electrical engineering awarded by the top 10 electrical engineering programs varied from about 10 per year at CalTech to about 80 per year at Stanford for a total of about 25\% of the number of doctorates in electrical engineering awarded by all US academic institutions.

\section{Results}

Table 1 shows the institutions from which the faculty at the top 10 electrical engineering research institutions obtained their doctorate. On average, 67\% of the EE/CS faculty received their doctorates from one of the top 10 electrical engineering research institutions. 
Approximately $75 \%$ of faculty members $(\mathrm{N}=480)$ at private institutions have doctorates from top 10 universities, as compared to $61 \%(\mathrm{~N}=697)$ at public institutions. However, if one includes other Ivy League universities and top international universities, nearly $80 \%$ of the electrical engineering faculty received their doctorates from one of the top 10 electrical engineering research institutions, an Ivy League school, or a top international university. Ninety percent of faculty members at private institutions and $73 \%$ of faculty members at public institutions belong to this category.

Further analysis of the data shows that 38\% ( $\mathrm{N}=1177)$ of all faculty and $57 \%(\mathrm{~N}=783)$ of those who received their doctorate at one of the top 10 research institution in the United States received their doctorate at one of the top three universities - MIT, Stanford or UC-Berkeley, even though these school produce less than $10 \%$ of the PhDs in electrical engineering. Public universities are in general more diverse and have a higher percentage of faculty members from non top 10 ranked institutions.

Table 1 - Percentage of Faculty at Top 10 Electrical Engineering Research Institutions with Doctorates from Top Graduate Programs

\begin{tabular}{|c|c|c|}
\hline & $\begin{array}{c}\text { Doctorates from Top 10 } \\
\text { Universities + Ivy League } \\
\text { Universities + International } \\
\text { Universities }\end{array}$ & $\begin{array}{c}\text { Doctorates from Top 10 } \\
\text { Universities }\end{array}$ \\
\hline MIT & 94 & 84 \\
\hline Stanford & 94 & 80 \\
\hline UC-Berkeley & 87 & 75 \\
\hline UIUC & 72 & 59 \\
\hline Georgia Tech & 71 & 60 \\
\hline CalTech & 93 & 89 \\
\hline CMU & 84 & 70 \\
\hline Michigan & 75 & 64 \\
\hline Cornell & 81 & 63 \\
\hline Princeton & 88 & 68 \\
\hline Purdue & 67 & 53 \\
\hline
\end{tabular}

Finally, between ten and twenty faculty members at these top 10 ranked universities who did not receive their doctorates from these top 10 ranked universities received their doctorates from the following institutions: Rice University, University of California Los Angles, University of California San Diego, University of Massachusetts - Amherst, University of Minnesota, University of Texas - Austin, University of Washington and University of Wisconsin - Madison.

Figure 1 shows the percentage of faculty at these top 10 institutions who received their doctorate from the same institution at which they are currently employed. The top three ranked universities - MIT, Stanford and UC-Berkeley along with CalTech - have more $20 \%$ of their faculty who have received doctorates from the same institution at which they are currently employed. MIT has the highest percentage of faculty, more than $40 \%$, who have received their doctorate from the home institution (MIT in this case) itself.

Proceedings of the 2013 American Society for Engineering Education Annual Conference \& Exposition Copyright (C) 2013, American Society for Engineering Education 
Fifteen percent of all the faculty members at these top 10 electrical engineering programs have received their doctorate from MIT, which produces about $3 \%$ of the number of doctorates in electrical engineering awarded by all US academic institutions, and $5 \%$ have received their doctorate overseas. MIT, Stanford and UC-Berkley are just about equally successful in placing the highest number of its graduates at other top ranked institutions. Besides the top three, CalTech, CMU and Princeton are the only institutions to have successfully placed their graduates at each of the top 10 ranked institutions.

While the 'myth' that $\mathrm{PhDs}$ are not hired at the institutions where they received their doctorates might be true at smaller institutions; it does not appear to be true at the top ranked institutions.

So what do these finding mean for graduate schools and graduate students? As the fraction of doctorates employed in tenure track positions in academia continues to decline and become highly competitive ${ }^{5}$, it might be more than ever important for graduate schools in general to redefine the $\mathrm{PhD}$ as also training for high-level positions in careers outside academia besides preparing them for an academic position.

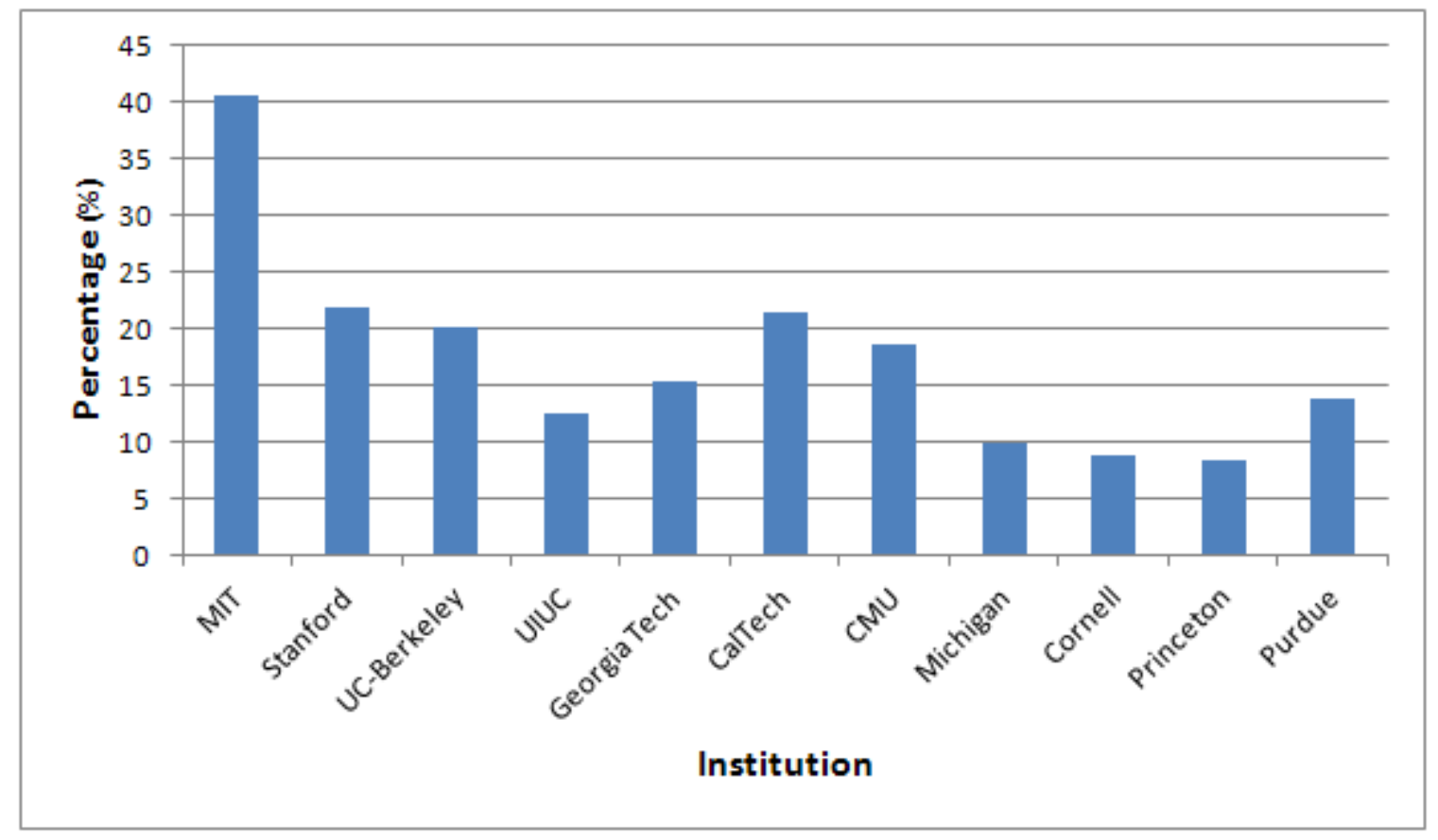

Figure 1 - Percentage of Faculty with Doctorate from the Home Institution

Traditionally, $\mathrm{PhD}$ programs place emphasis on providing teaching and research opportunities to students as preparation for academic careers. For those that move into finding alternate nonacademic careers, additional skill training may prove useful. Thus the program could focus on training of the mind, student development, mandatory graduate internships, structured required courses in entrepreneurship, global education and research, presentation, proposal and report writing and other transferable skills ${ }^{5,8}$. In addition, it is recommended and desirable to have at least one member of the doctoral thesis committee from industry. 
It may be wise for $\mathrm{PhD}$ programs to combine with management programs and offer a joint $\mathrm{PhD} /$ MBA degrees so that graduates who may become technical leads at companies get not only depth in their area of expertise but also gain requisite management skills to lead groups.

Finally, while these results in general may apply to other engineering disciplines, this study has focused strictly on the EE/CS programs. However, it appears that the hiring patterns are similar at the top research universities based on the data for EE/CS, mechanical engineering, history and economics.

\section{Conclusions}

This study looks at the distribution of electrical engineering and computer science faculty members at the top 10 ranked electrical engineering programs and where they received their doctorate. More than $67 \%$ of faculty members at the top 10 ranked institutions have received their doctorate from these institutions themselves, and that $38 \%$ of all faculty and $57 \%$ of those who received their doctorate at one of the top 10 research institution in the United States received their doctorate at one of the top three ranked universities - MIT, Stanford and UCBerkley. If one includes other Ivy League universities and major international universities, this number increases to nearly $80 \%$. More than $40 \%$ of MIT faculty members have received their doctorate from MIT itself. Top public universities are in general more diverse than their private counterparts and have a higher percentage of faculty members from non top 10 ranked institutions. MIT, Stanford and UC-Berkley are just about equally successful in placing the highest number of its graduates at other top ranked institutions. Besides the top three, CalTech, CMU and Princeton are the only institutions to have successfully placed their graduates at each of the top 10 ranked institutions. Thus it appears that the institution where graduates receive their doctorate affects their employability as a faculty member at the top 10 ranked electrical engineering programs.

\section{Bibliography}

1. http://talk.collegeconfidential.com/graduate-school/820076-does-matter-where-you-do-your-phd.html

2. Wu, S., “Where Do Faculty Receive Their PhDs?” Academe Online, Jul.-Aug. 2005. http://www.aaup.org/AAUP/pubsres/academe/2005/JA/Feat/wu.htm

3. Townsend, R. B., "New Study Highlights Prominence of Elite PhD Programs in History," Perspectives, October 2005.

4. Saigal, A. and Saigal, A.K., "Faculty Hiring Patterns in Mechanical Engineering at Elite Universities," Proceedings of 2012 ASEE Annual Conference, San Antonio, TX, June 10-13, 2012, AC2012-3690.

5. Cyraniski, D., Gilbert, N., Ledford, H., Nayar, A and Yahia, M, "Education: The PhD Factory,” Nature, 472, 2011, pp. 276-279.

6. “Top Electrical Engineering Schools,” 2012. http://grad-schools.usnews.rankingsandreviews.com/best-graduate-schools/top-engineeringschools/electrical-engineering-rankings 
7. Science and Engineering Doctorates: 2011, National Center for Science and Engineering Statistics, National Science Foundation, 2011. http://www.nsf.gov/statistics/sed/2011/data_table.cfm

8. Stephan, P. E., Sumell, A. J., Black, G. C. and Adams, J. D., "Doctoral Education and Economic Development: The Flow of New Ph.D.s to Industry,” Economic Development Quarterly, May 2004, pp. 151-167. 